\title{
Cyclical hematuria-ureteral endometriosis: a case report
}

\section{Sindura Ganga Ravula*, Harish Shetty, Aparna Rajesh}

Department of Obstetrics and Gynecology, KS Hegde Medical Academy, NITTE University, Mangalore, Karnataka, India

Received: 18 January 2018

Accepted: 28 February 2018

\section{*Correspondence:}

Dr. Sindura Ganga Ravula,

E-mail: sindu.ravula@gmail.com

Copyright: (c) the author(s), publisher and licensee Medip Academy. This is an open-access article distributed under the terms of the Creative Commons Attribution Non-Commercial License, which permits unrestricted non-commercial use, distribution, and reproduction in any medium, provided the original work is properly cited.

\begin{abstract}
Little attention has been paid for the renal involvement in endometriosis, a rare and silent disorder which ultimately lead to renal failure. Involvement most commonly may be limited to single ureter (left one) and it is usually involvement extrinsically. Although cases have been reported in the literature, true incidence of ureteral involvement is still not known. The diagnosis is difficult as the disease has non-specific symptoms. Only high index of suspicion with radiological support would be helpful in early diagnosis. Early cases may be benefited with progestin or Antiaromatase therapy, most cases need surgery, either laparoscopically or laparotomy.
\end{abstract}

Keywords: Endometriosis, Hematuria, Hydronephrosis, Ureter, Ureteroscopy

\section{INTRODUCTION}

Endometriosis is a benign gynaecological condition characterised by the presence of the functional endometrial tissue outside the uterus. It usually involves the ovaries, fallopian tubes, rectovaginal septum, cul-desac, and pelvic peritoneum. Various other sites of involvement of endometriosis has also been observed, such as, skin, lungs, brain, gastrointestinal tract, umbilicus and the genitourinary tract.

Involvement of genitourinary tract has been described as $1.2 \%$. Most commonly involving the bladder $(85 \%)$, the ureter $(15 \%)$ and very rarely the urethra. ${ }^{1}$ Ureteral endometriosis accounts for $<0.3 \%$ of all types of endometriosis. $^{2}$

Usually the involvement of the ureter is unilateral, and in more than $80 \%$ of the cases it is found on the left side, below the level of the pelvic brim (distal ureteric involvement) and can lead to urinary tract obstruction, hydroureteronephrosis and loss of renal function. ${ }^{3}$ The two pathological types of ureteral endometriosis are extrinsic and intrinsic. Extrinsic one is the most common type accounting for about $80 \%$ of the cases, characterised by the presence of the endometrial glands and stroma within the submucosa and adventitia of the ureter. Whereas, intrinsic ureteral endometriosis accounts for about $20 \%$ of the cases and is characterised by the involvement of the uroepithelial and the submucosal layer.

Pelvic endometriosis most commonly presents with dysmenorrhoea, Dyspareunia, pelvic pain, menorrhagia. Urinary tract involvement is characterised by the presence of haematuria. The incidence of cyclical haematuria with ureteral endometriosis is $15 \%$. It is commonly seen with intrinsic ureteral endometriosis. ${ }^{4}$ As the incidence is rare and the absence of specific symptoms for ureteral endometriosis it is often overlooked and presents as a challenge for the diagnosis and treatment. Pre-operative diagnosis is essential in management and reducing the incidence of the renal dysfunction. 


\section{CASE REPORT}

A 37-year-old woman, P2 L3 presented to the outpatient Department of Obstetrics and Gynaecology with complaints of progressive congestive dysmenorrhoea, dyspareunia, pelvic pain for 3years. She was diagnosed with bilateral ovarian endometriosis and was managed medically for a period of 6 months with Dienogest. Following which she was symptomatically better. 6months later she started having cyclical haematuria, concurring with the menstruation and was evaluated for the same.

Abdominal ultrasound done revealed bulky retroverted uterus with bilateral ovarian endometriomas, associated grade 3 hydronephrosis with dilatation of the proximal ureter on the left side at the level of the iliac vessel.

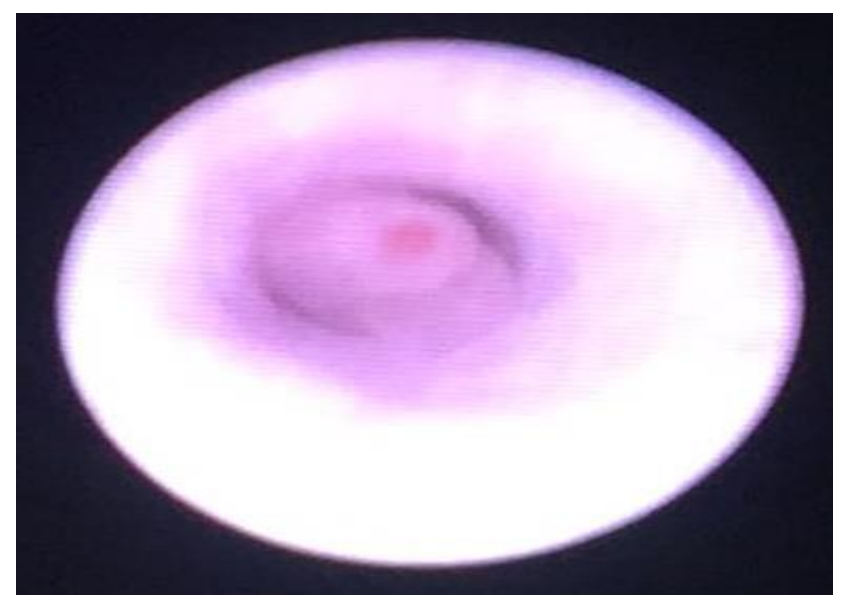

Figure 1: Diagnostic cysto-ureteroscopy of the left ureter showing a growth in the wall of the distal ureter.

Urine cytological examination revealed no malignant cells. Blood Urea - 29.7, Creatinine - 1.03, Uric acid 4.1. Following which a Pelvic MRI along with MR Urogram revealed Moderate left hydroureteronephrosis with atrophy of the renal parenchyma. Non Visualisation of the distal ureter below the level of the iliac vessels. Bilateral slightly enlarged ovaries.

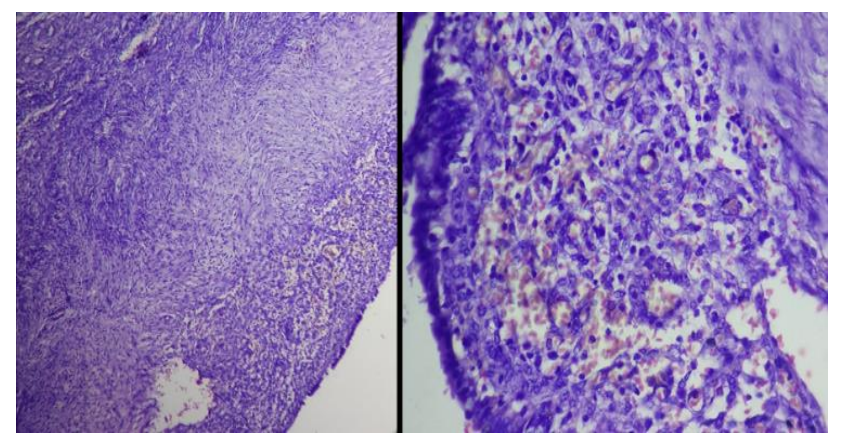

Figure 2: Left ovary (H \& E) 10X (left side) -Sparse endometrial stroma, 40X (right side) -hemosiderin laden macrophages and areas of haemorrhage.
Diagnostic Cysto-Ureteroscopy revealed normal bladder mucosa and a growth of $0.7 \times 0.5 \mathrm{~cm}$ in the distal ureter, $5 \mathrm{~cm}$ proximal to vesicoureteric junction, scope could not be negotiated beyond this growth. She underwent total abdominal hysterectomy with bilateral Salphingo oophorectomy with left ureteroneocystostomy. Intraoperatively dense adhesions were noted between the left ureter and the ovary.

Histopathological examination of the specimen revealed bilateral ovarian endometriosis with the presence of multiple foci of endometrial glands and stroma within the ureter with denuded mucosa confirmed the diagnosis of intrinsic ureteral endometriosis as a cause of the cyclical haematuria.

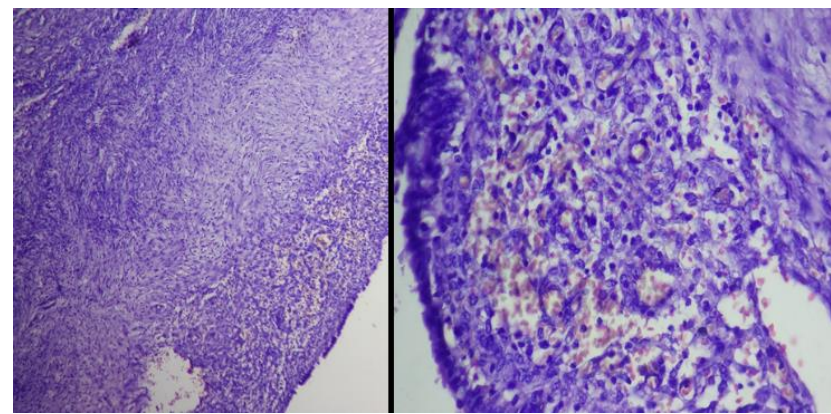

Figure 3: Right ovary (H \& E) 10X (left side)Endometrial glands and stroma, 40X (right side) columnar epithelium with haemorrhage and endometrial stroma.

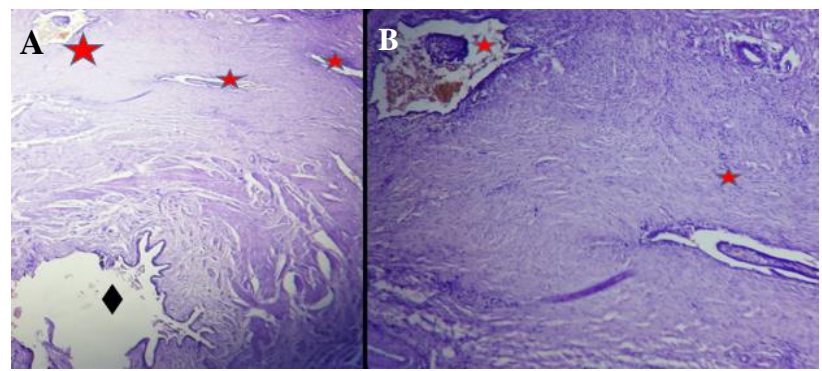

Figure 4: A (H and E) 4x- ureter lined by transitional epithelium with endometrial glands in the adventitia

B (H and E) 10x- endometrial glands lined by columnar epithelium and sparse endometrial stroma.

\section{DISCUSSION}

Urinary tract involvement is reported in $1-4 \%$ of the cases with endometriosis. ${ }^{5}$ The most common location being bladder followed by the ureter, kidneys and lastly the urethra. Ureteral endometriosis is rare occurring in about $0.1-1 \%$ of the women with endometriosis. Majority of these patients are asymptomatic and have very nonspecific symptoms. They are always at a high risk for the development of renal dysfunction and silent kidney loss if left untreated. Early diagnosis of such cases would help in the reduction the morbidity and associated 
consequences such as renal dysfunction and hydroureteronephrosis.

Appropriate imaging findings and evaluation help in identifying all the sites of endometriosis preoperatively. Asymmetric ureteric involvement is reported in majority of the cases so far. Ureteral involvement is mainly due to the spread of deep endometriosis infiltrating the rectovaginal space or uterosacral ligaments.

The purpose of treatment of ureteral endometriosis is to relieve the ureteral obstruction and prevention of renal dysfunction and treatment of the associated pelvic endometriosis. The goal of management of ureteral endometriosis should be individualized and depends upon the extent of the pelvic and ureteric disease and the degree of impairment of the renal function.

Hormonal therapy to suppress the ovarian function is preferred only in initial stages of the disease, due to higher incidence of recurrence in the advanced stage of the disease. ${ }^{4}$ Hormonal therapy is best preferred for the women in childbearing age group, however the recurrence with the ovarian preservation is $27 \%$, in contrast to the recurrence rate of only $3 \%$ after total abdominal hysterectomy with bilateral Salphingooophorectomy. ${ }^{6}$

The main aim of the surgical treatment is to remove the source of oestrogen and thus making the extrinsic endometrial tissue inactive. Extrinsic endometriosis with mild hydroureteronephrosis is managed by ureterolysis, whereas the cases of moderate to severe hydroureteronephrosis or with intrinsic ureteral endometriosis must be managed with resection of the involved ureteral segment with primary ureteroureterostomy or ureteral reimplantation with psoas hitch and / or boari flap. ${ }^{7}$

\section{CONCLUSION}

Ureteral endometriosis is a rare disease, among the women in reproductive age group, presenting with cyclical haematuria. Due to rare incidence and nonspecific symptoms majority of these cases are left underdiagnosed at the time of presentation. Most of them at a later stage develop a silent kidney loss and hence they should always be evaluated with a very high index of suspicion, to prevent renal failure. Open or laparoscopic surgical treatment is needed for the extensive disease, hormone therapy with close surveillance of kidney function must be offered as the first line of treatment.

Funding: No funding sources Conflict of interest: None declared Ethical approval: Not Required

\section{REFERENCES}

1. Hornstein, M. Leuprolide Acetate Depot and Hormonal Add-Back in Endometriosis: A 12-Month Study. Obstet \& Gynecol. 1998;91(1),16-24.

2. Nezhat C, Nezhat F, Nezhat CH, Nasserbakht F, Rosati M, Seidman DS. Urinary tract endometriosis treated by laparoscopy. Fertility and sterility. 1996;66(6):920-4.

3. Body, G. Muteganya, D. Descamps, P. Janin, P. Nivet, H. \& Lansac, J. Ureteral endometriosis revealed by an acute renal failure. Eur J Obstet Gynecol Reprod Biol. 1996;67(1),53-57.

4. Yohannes, P. Ureteral Endometriosis. J Urol. 2003; 170(1),20-25.

5. Pérez, M., Bazán, A., Alonso Dorrego, J., Hernández, A., de Francisco, M., \& Hernández, M. et al. Urinary Tract Endometriosis: Clinical, Diagnostic, and Therapeutic Aspects. Urology. 2009; 73(1),47-51.

6. Takeuchi, S., Minoura, H., Toyoda, N., Ichio, T., Hirano, H., \& Sugiyama, Y. Intrinsic Ureteric Involvement by Endometriosis: A Case Report. J Obstet Gynaecol Res,1997;23(3),273-276.

7. el Khader k, Guille F, Patard J, Mhidia A, Ziade J, Manunta, A. (1998). Ureteral reimplantation on psoas bladder: long-term results. Acta Urol Belg, 66:15.

Cite this article as: Ganga RS, Shetty H, Rajesh A. Cyclical hematuria-ureteral endometriosis: a case report. Int J Reprod Contracept Obstet Gynecol 2018;7:1648-50. 